\title{
Appendix: Questionnaire for complement control and control predicates ${ }^{\#}$
}

\section{Introduction}

This questionnaire focuses on control structures that are instantiated by predicates that take a state of affairs (SOA) argument. Noonan (1985) has called these predicates 'complement-taking predicates'; I will use the notion of SOAAtaking predicates (SOAA $=$ state of affairs argument).

Prototypically, complement control is instantiated by certain classes of verbs; however, adjectives (be eager to) and nouns (e.g. nominalizations such as promise) may function as control predicates as well. 'Control' refers to the pattern of argument identification between an argument of the SOAA-taking predicate and an argument of the SOAA-head. In the literature the notion of 'equi deletion' or 'equi-NP deletion' has been used (following Rosenbaum 1967), which refers to structures in which an overt argument of the matrix predicate is identified with a covert argument of the embedded predicate. This questionnaire aims at a crosslinguistic application of the notion of control and thus uses a semantic definition of complement control. It extends the notion of control to other patterns of referential dependency between arguments of a SOAA-taking predicate and of the embedded predicate.

The questionnaire is based on the following definition of obligatory control:

Definition of obligatory control

Obligatory control applies to structures in which a predicate $\mathrm{P}_{1}$ selects a SOA-argument and requires one of its (individual) arguments to be (improperly) included in the set of referents of an argument of the embedded predicate $\mathrm{P}_{2}$ heading the SOA-argument.

$$
\left[\mathrm{X}_{\mathrm{i}} \mathrm{P}_{1}\left(\mathrm{Y}_{\mathrm{j}}\right)\left[\mathrm{Z}_{\mathrm{k}} \mathrm{P}_{2} \ldots\right]_{\text {SOA }}\right] \text { with } \mathrm{k} \cap\{\mathrm{i}, \mathrm{j}\} \neq \varnothing
$$

From this viewpoint, a selectional restriction between a predicate and a SOAargument and the referential dependency between an argument of the matrix predicate and an argument of the dependent predicate are the prerequisites for complement control.

Following the general terminology I will call the argument that establishes the referential reading the controller and the argument whose referential interpretation is dependent on some other argument the controllee. The controllee

\# This questionnaire replaces the one that has been used in the project Typology of control verbs, funded by the German Science Foundation (DFG; STI 151/2-2) and directed by myself. 
may be covert or a pronominal element. In forward control, which represents the prototypical case, the controller is in the matrix clause (i.e. the arguments $\mathrm{X}$ or $\mathrm{Y}$ in (1)) and the controllee in the embedded clause (argument Z). In backward control, the relation is reversed, i.e. the controller is in the embedded clause and the controllee in the matrix clause.

(1) subsumes the following control readings, whereby $\mathrm{k}, \mathrm{i}$, and $\mathrm{j}$ refer to the referential indices of $\mathrm{Z}, \mathrm{X}$ and $\mathrm{Y}$ and $\mathrm{v}$ to some disjoint referent:

(2) Control readings of (1)

$\begin{array}{lcc} & \text { Subject control } & \text { Object control } \\ \mathrm{k}=\mathrm{j} \\ \text { exhaustive } & \mathrm{k}=\mathrm{i} & \mathrm{k}=\mathrm{j}+\mathrm{v} \\ \text { Partial } & \mathrm{k}=\mathrm{i}+\mathrm{v} & \mathrm{k}=\mathrm{i}+\mathrm{j}\end{array}$

The definition of obligatory control in (1) takes finite SOA-arguments, overt pronominal controllees, control in subject clauses, and non-exhaustive control readings into consideration, thus deviating from many syntactic approaches.

Complement control is a core phenomenon of the lexicon-syntax interface. General syntactic properties of the language (e.g. the general structure of sentential complementation in the respective language) interact with the lexical properties of the particular SOAA-taking predicate. The degree to which syntax and lexicon/semantics play a role is language-specific. This questionnaire aims to target both general syntactic properties and predicate-specific properties. Therefore, some questions deal with the syntax of the respective language and its control structures and some with the specific properties of the SOAA-taking predicates. The questions are based on insights into control predicates of well-studied languages.

Given that raising verbs are also instances of complex predicates, it is important to distinguish control predicates from raising predicates (e.g. seem). Raising occurs if an argument of the embedded predicate is realized as a complement/the subject of the matrix predicate, yielding a semantics-syntax mismatch: semantically, the argument belongs exclusively to the embedded predicate, syntactically to the matrix predicate.

Besides the well-known cases of subject raising (Peter seems to be hungry) and object raising (also ACI verbs or ECM verbs: she believes him to be a liar), there are structures that have been analyzed as object-to-subject raising (generally dubbed tough-movement: John is easy to please) or object-to-object raising. However, these structures seem to preclude the raising of expletive arguments; therefore, these structures cannot be analyzed as raising structures proper.

One distinctive feature of raising predicates is that they allow the raising of expletives, whereas control predicates cannot embed predicates whose control- 
lee would be an expletive. Therefore, the admissibility of 'weather verbs' or other impersonal verbs is an indication of a raising structure.
a. It seems [to rain].
b. *John wants [_ to rain].
c. John wants [it to rain].

[raising verb]

[control verb variant]

[raising verb variant]

Furthermore, the truth conditions of sentences containing raising verbs do not change if the embedded verb is passivized.

a. She seems [to prefer red roses].

b. Red roses seem [to be preferred by her].

In contrast, control relations are affected by passivization of the embedded predicate, as different buletic situations are characterized by the following sentences:
a. I want [ _ to praise them].
[wish to praise]
b. I want [ _ to be praised].
[wish to be praised]

Often languages display a number of predicates that have both a raising and a control variant.'want' is a typical example (cf. (6a/b)); other verbs may have such a double function as well (cf. (6c-e)):

a. Mary wants [ _ to sing].

b. Mary wants [him to sing].

[subject control]

c. Peter droht ${ }_{-}$die [object raising] $P$ threatens the door in-to-smash.INF 'Peter threatens to smash the door'

d. Peter droht [in den Keller zu fallen]. $\mathrm{P}$ threatens in the cellar to fall.INF 'Peter threatens to fall into the cellar'

e. Es droht [zu regnen]. it threatens to rain.INF 'it threatens to rain'

[subject raising]

Not all criteria that may distinguish raising from control are applicable in all languages. In German, for instance, subject control predicates are distinguished from subject raising predicates by their potential to be passivized. (6c) can thus be passivized, (6d) cannot.

Raising of DPs/NPs should be differentiated from long scrambling or similar movement processes in terms of the observable effect in argument linking: the raised DP/NP receives a linker by the matrix verb, not by the embedded verb. There is one systematic exception to the general pattern: In most languages, DPs/NPs that are lexically marked by the embedded predicate do not allow this 
linker to be overridden by the matrix predicate; hence, the linking effect should not occur with lexically marked arguments.

\section{The language profile}

Some background information is needed in order to capture all relevant aspects of complement control. The following questions help to highlight the relevant structural properties of the respective language.

2.1 Unrealized arguments: Does the language allow pro-drop, i.e. the dropping of unemphatic personal pronouns (as subjects or objects)? Does the language allow topic drop?

In order to avoid that structures of pro-drop or topic drop in embedded clauses are mistaken as instances of complement control, it is important to check the potential referents of the unrealized argument: If there is no requirement that the referent of the unrealized argument (improperly) includes the referent of one of the arguments of the matrix verb, the respective structure should not be analyzed as an instance of complement control.

\subsection{Argument linking}

Argument linking may influence control; for instance, a language may exclude oblique arguments from being controlled, which affects the selection of the controllee. With respect to controller choice, there is no strict evidence that the selection of the controller correlates with a certain pattern of argument realization. However, there may be languages in which argument linking does play a role in terms of the controller.

2.2.1 Does the language exhibit morphological case? If so, which kind of linker inventory does it have (e.g. accusative/nominative, ergative/nominative, ergative/ accusative/nominative)?

2.2.2 Does the language have oblique linkers (morphological case or adpositions)?

2.2.3 Does the language exhibit predicates with lexically induced argument linking?

In lexically induced argument linking certain predicates deviate from the canonical linking pattern, e.g. the following German transitive predicates that do not realize their object with accusative (ACC) and their subject with nominative (NOM) but instead with dative (DAT) or genitive (GEN).
a. helfen 'help' DAT-NOM/*ACC-NOM
b. gefallen 'like'NOM-DAT/*ACC-NOM
c. gedenken 'commemorate' GEN-NOM/*ACC-NOM 
2.2.4 Does the language exhibit verbal agreement? If the language has object agreement: Does the verb agree with a SOA-argument?

2.2.5 If the language lacks morphological case and/or agreement: Does it exhibit a positional linking system, i.e. are arguments identified by their position?

2.2.6 Does the language exhibit a linking system that does not operate in terms of structural case, i.e. does the language make use of an

- active/inactive system,

- inverse system (as in the Algonquian languages),

- Philippine-style voice system,

- another system?

\subsection{Voice system}

2.3.1 Does the language have passive and/or antipassive? What are its properties? Is an oblique realization of the demoted argument possible? Is the demoted argument excluded from being overtly realized?

Voices such as passive may affect control, changing the control relation. It may be the case that some control predicates cannot be passivized or only under certain conditions. Moreover, passivization of the embedded predicate may lead to a shift of the controllee, yielding control of the theme argument.

2.3.2 Does the language make use of diathesis operations that introduce new arguments (causative, applicative)?

Since argument-extending diathesis operations affect the argument structure of predicates, they may affect control relations as well.

2.4 Phrasal constituency: Which tests are applicable in the respective language to determine phrasal constituency (movement processes, pronominalization, special-position clitics etc.)?

These tests may help to distinguish forward control from backward control (see 3.6).

\subsection{Sentential complementation}

2.5.1 Which types of sentential complementation are attested in the respective language?

- parataxis

- finite complement clauses

- infinitival complement clauses 
- participial or other types of infinite complement clauses

- nominalization

Please indicate their range of use and frequency. Indicate whether the various types may occur with or without a complementizer.

2.5.2 Does any of the attested types of sentential complementation exhibit restrictions on the realization of the arguments of the embedded head, i.e. does one argument have to remain covert (e.g. as often is the case, e.g. with infinitives)?

This is an important aspect of the study of complement control. Structures that require one argument to remain covert can only be licensed by raising or control predicates. ${ }^{1}$ These structures will be termed 'control-inducing' in the following. Structures that allow all arguments to be realized within the domain of their functor are called 'control-neutral'.

2.5.3 Do these types of sentential complementation show the same structural potential as matrix clauses, i.e. do they allow

- the same patterns of agreement,

- the same tense/aspect/mood markers,

- the same polarity markers,

- the same voice distinctions?

Differences in the structural potential may motivate differences in the class of the licensing matrix predicates. Factive predicates or utterance predicates preferentially occur with sentential complementation structures that allow the full range of tense/aspect/mood marking.

2.5.4 Do dependent clauses differ from matrix clauses in terms of word order?

2.5.5 Does the language make use of complex predicates? Especially, does it show

- verb incorporation or verb-verb compounds,

- affixal verbs (as in Greenlandic),

- serial verb constructions?

Complex predicates generally require argument sharing/identification unless they trigger raising. Please indicate the types of argument sharing, i.e. which arguments of the head predicate are shared with which arguments of the non-head predicate.

1 In some cases, e.g. with nominalized sentential complements, restrictions on argument realization may only show up with polyvalent embedded predicates. Likewise, in some types of sentential complementation the realization of the respective argument may be excluded only in certain structural contexts. 
2.5.6 Which of the attested complementation types are used with SOAarguments (including subject clauses), i.e. clauses that are semantically selected by the matrix predicate?

2.5.7 Which of the attested types are used with SOA-adjuncts, especially with purpose clauses (he came to see the exhibition, he called her in order to learn about her new friend)?

This question aims at the potential parallels between structures of complement control and purpose clauses because they latter often also show control.

2.5.8 Does the language have a switch-reference system? Please list the markers for same subject (SS) and different subject (DS). What is their distribution in terms of the structures they may occur in?

Although switch-reference markers are not attested systematically for structures of complement control, there may be languages that may use a switch-reference system in complement control.

2.5.9 Does the language distinguish between structural and oblique sentential complementation?

A SOA-argument may be realized obliquely by direct oblique case marking (e.g. with nominalized complements) or indirect oblique case marking (correlative pronouns in the matrix clause). Although languages may lack oblique markings on SOA-arguments, the SOA-arguments may still be non-structural, which may be indicated by the lack of object agreement or the failure to undergo clause union/restructuring. The Mayan language Q'eqchi' exhibits both oblique and structural SOA-arguments. Oblique SOA-arguments have an oblique complementizer (chi) as in (8a) and lack object agreement; they only have an N-agreement marker (nominative/absolutive), indexing the subject. With structural SOAarguments the oblique complementizer is not present as in (8b), and the subject is indexed by ergative agreement (E-marker), whereas the SOA-argument is indexed by the non-overt 3SG.N-marker.

Q'eqchi' (Kockelman 2003:30)
a. X-in-lub [chi k'anjelak $]$ PERF-1SG.N-tire COMP.OBL work 'I got tired of working'
b. n-inw-aj [xik sa' li k'ayil] PRES-1SG.E-want Go into the market 'I want to go to the market'




\section{General properties of the language's control structures}

This section deals with the general properties of complement control, i.e. the type of instantiated sentential complementation, the admissibility of backward control, WH-control and control in subject clauses. The predicate-specific properties are dealt with in 9.

3.1 Which structures of sentential complementation that require argument identification with some argument of the matrix predicate (= 'controlinducing' structures) are used with SOAA-taking predicates?

Typically, structures with infinite heads are potential candidates for this type of sentential complementation. In languages that do not have control-inducing structures control is confined to certain predicates that require a control reading independent of the type of sentential complementation (see question 3.3). If the language exhibits several types of control-inducing structures, please indicate the differences between these structures in terms of control and non-control properties.

3.2 Which structures of complex predicates are used with SOAA-taking predicates?

Not all languages that have complex predicates use them in complement control. A language may have, for instance, serial verb constructions, but exclude them for SOAA-taking predicates. Likewise, a language may limit verb incorporation to raising predicates.

3.3 Are there instances in which a SOAA-taking predicate selects a controlneutral structure and requires a control reading even in this type of sentential complementation?

Recall that control-neutral structures are those structures that do not require argument identification with some argument of the matrix clause and may link all arguments of the head predicate within its linking domain. Predicates that require a control reading with these types of sentential complementation are inherent control predicates.

3.4 Do structures of complement control differ from purpose clauses?

Purpose clauses may instantiate control-inducing structures as well. Therefore, it is worthwhile to compare these clause types (he came in order to hear about the latest news) with structures of complement control. The question is whether the status as SOA-adjunct (purpose clause) vs. SOA-argument (complement control) has any consequences.

3.5 Are there structural restrictions regarding the embedded predicate? 
Given that languages may restrict structures of sentential complementation to intransitive predicates (e.g. in some Mayan languages) one should check whether there are structural restrictions with some or all of the types of sentential complementation.

\subsection{Backward control}

As mentioned above, backward control reverses the relation of controller and controllee: the controller is in the embedded clause, the (covert) controllee in the matrix clause , indicated by '_, (see Polinsky \& Potsdam 2002a, 2002b):

$$
\left[{ }_{\mathrm{i}} \mathrm{P}_{1}\left(\mathrm{DP}_{\mathrm{j}}\right)\left[\mathrm{DP}_{\mathrm{i}} \mathrm{P}_{2} \ldots\right]_{\mathrm{SOA}}\right]
$$

3.6.1 Does the language allow backward control?

Please indicate which structural properties suggest that the controller is realized within the embedded clause (e.g. scrambling of the complement clause), the position and interpretation of adverbials, ellipsis, agreement patterns).

3.6.2 Which predicates license backward control? Is forward control also possible with these predicates?

Usually, the set of licensing predicates is rather small (e.g. certain phasal predicates, certain directive predicates).

3.6.3 Is there a semantic difference between forward and backward control?

Maria Polinsky (p.c.) has pointed out that the difference between forward and backward control tends to be one of implicative vs. non-implicative readings regarding the SOA-argument. There may also be scopal differences in interpretation.

3.6.4 Which kinds of quantificational controllers are possible in backward control?

Quantifiers are usually in a structurally higher position than the variables bound by them. Backward control thus poses a structural challenge to quantificational controllers because the quantificational controller is lower than the variable (i.e. the controllee). The Caucasian language Tsez, for instance, excludes quantificational controllers in backward control.

\subsection{Control in embedded questions (WH-control)}

In some languages control structures can also be found with embedded questions. Typically, these are languages in which control-inducing structures are compatible with interrogative predicates.

3.7.1 Does the language allow control-inducing structures with interrogative predicates? 
3.7.2 Which interrogative predicates select control-inducing structures?

Not all interrogatives that select, for instance, finite embedded questions also select embedded questions with control-inducing structures. Besides interrogative predicates (wonder, ask), which instantiate intensional embedded questions (he wondered [how _to reach the summit]), one can also find non-interrogative predicates with embedded questions, which are cases of extensional embedded questions (she cabled Helen [when _to send the package]):

3.7.2 Are there non-interrogative predicates that license embedded questions with control-inducing structures?

3.7.3 Are there interrogative predicates that require a control reading independent of the instantiated complementation structure?

Even languages that do not exhibit control-inducing structures or that do not allow interrogative predicates with control-inducing structures could have interrogative predicates that require a control reading, independent of the type of sentential complementation. So far, no cases have been attested, but the existence of these predicates cannot be ruled out completely.

Regarding the control readings in WH-control, I refer to question 6.4.

\subsection{Control in subject clauses}

Many SOAA-taking predicates select a SOA-argument as internal (lowest) argument, hence as object. There are some predicates in which the SOA-argument is analyzed as subject. Depending on the characterization of subject, a subject clause is one in which the SOA-argument corresponds to the highest argument in the argument structure (highest-argument subject clause) or one in which a pronominalization of the clause would yield the default linker (NOM-linker subject clause). The agreement pattern (3SG on the matrix predicate) is another superficial morphosyntactic criterion that points into the direction of the second criterion. Under the second view, intransitive SOAA-taking predicates with an implicit argument, which may be realized obliquely, are assumed to take subject clauses. The interesting case, however, is a SOA-argument being higher in the argument hierarchy than any potential controller. Therefore, the two notions of subject clauses should be distinguished.

3.8.1 Are there instances of obligatory control with highest-argument subject clauses?

Potential candidates are (causative) experiencer-object verbs such as disturb, amuse, thrill ..., in which the higher stimulus may be a SOA-argument. It is important to check whether these verbs truly behave as control verbs (requiring (improper) inclusion between controllee and controller). 
3.8.2 Are there instances of obligatory control with NOM-linker subject clauses?

If the predicate has an implicit argument, it is expected to be the controller. If the SOA-argument is the single argument, there cannot be any local controller. In order to identify the potential control readings, it is important to check whether one can enforce a reading in which the non-SOA-argument of the matrix predicate is excluded as controller as in (10a). ${ }^{2}$

(10) a. [ _arb:gen to smoke around babies $\mathrm{j}_{\mathrm{j}}$ is dangerous for them $\mathrm{j}_{\mathrm{j}}$.

b. [ _ _i/??gen to smoke around babies $\left.\mathrm{j}_{\mathrm{j}}\right]$ is dangerous for Peter ${ }_{\mathrm{i}}$.

\section{The controllee}

Since Keenan (1976) the control pattern in terms of the controllee has been taken as a subject criterion. The selection of the argument to be controlled is generally not predicate-specific but determined by the grammar of the respective language. However, there may be exceptions such as Tagalog, in which certain modal contexts or certain predicates are not confined to one pattern of controllee choice. This section deals with the language-specific restrictions on controllees. Recall that controllees tend to be covert, but can be pronominal as well.

4.1 Which argument is selected as controllee in the unmarked case?

a) the semantically highest argument irrespective of its case marking (= actor control)

b) the argument that would receive the default linker (nominative/ absolutive) (= NOM control)

Usually, languages choose one option (e.g. actor control in Icelandic, NOM control in German). However, there are languages that allow the other option in certain contexts (see 4.3).

4.2 Does the language allow the controllee to be a lexically designated argument (i.e. an argument that would surface with a lexical/oblique case in non-control structures)?

Languages with actor control should allow lexically designated controllees unless they require the lexical/oblique case to be visible, which is in conflict with covert controllees. Languages with NOM control should exclude lexically designated controllees.

2 The index 'arb' indicates arbitrary control, which is actually non-control. 'gen' indicates a generic reading. See section 6 . 


\subsection{Controllee shift}

4.3.1 Languages with unmarked actor control: Does the language allow NOM control in certain contexts? If so, what are the contexts (e.g. certain tense/aspect/mood configurations, certain matrix predicates)?

4.3.2 Languages with unmarked NOM control: Does the language allow actor control in certain contexts? If so, what are the contexts (e.g. certain tense/aspect/mood configurations, certain matrix predicates)?

These two patterns of controllee shift are principled shifts in terms of actor or NOM control. Another potential shift is one that does not affect the general controllee selection strategy but shifts the controllee within the NOM or actor control paradigm:

4.3.3 Is the control relation affected by voice or diathesis operations on the embedded predicate such that the controllee is shifted?

Passivization of the embedded predicate, for instance, yields a controllee shift in NOM control:

(11) a. John wants [ _ to invite Mary].

controllee $=$ agent

b. John wants [ _ to be invited].

controllee $=$ patient

Actor control is incompatible with such a shift; in actor control, controllees can only be shifted if the highest argument is no longer semantically accessible; then, the next-to-highest argument should become controllee.

Other diathesis operations can affect the control relation as well. In languages with NOM control, control of a NOM object is possible if the highest argument is linked by a non-default linker. An applicative that introduces a new object and renders the base object oblique should turn the new object into the controllee.

\section{The controller}

The central question regarding the controller is whether its selection is mainly predicate-specific (or specific for a semantic class of predicates), which crosslinguistic data suggest, or whether it is determined or influenced syntactically a cross-linguistically rare option.

5.1 Does the language impose syntactic constraints on the selection of the controller?

The only attested case so far for a strict syntactic selection of the controller are the Austronesian language Kavalan and its closest relatives (Chang \& Tsai 2001) and the Mayan language Mam (concerning cases of infinitival comple- 
ments, see England 1989), both discussed in the preceding paper. A syntactically determined controller choice is bound to certain syntactic configurations. Please indicate the admissible syntactic configurations for controllers.

5.2 In languages with syntactic controller choice: Does the language apply repair strategies in order make certain arguments accessible as controllers or to establish a control relation at all?

Kavalan shows one kind of repair strategy: the causativization of the embedded predicate in order to preserve actor subject control. Diathesis operations on the matrix predicate or on the embedded predicate represent the expected repair strategies.

5.3 Does the language allow oblique controllers (e.g. agent phrases in passive, oblique objects)?

5.4 Does the language allow implicit control (e.g. Mary signalled $(X)$ L_X $_{\text {to }}$ follow her])? Are there predicates with obligatorily implicit control?

Please indicate whether there is a specific linking pattern for implicit arguments/controllers in case they are overtly realized. If there is no specific linking pattern for implicit arguments, this may be taken as indication that the control relation is established on semantic grounds and not on configurational grounds.

5.5 For languages that instantiate a switch-reference system in complement control: Indicate the use of switch-reference markers with cases of subject and object control.

\section{Referential dependencies between controller and controllee}

The various control verbs differ in their potential referential dependencies between controller and controllee. One can find:

- exhaustive control: the referents of controller and controllee overlap completely,

- partial control: the referent of the controller is (properly) included in the referents of the controllee ( Peter $_{i}$ wants $\left[{ }_{-}{ }^{i+v}\right.$ to meet at six]),

- split control: two arguments of the control predicate jointly control the controllee,

- generic control: the controller is generically bound (it is easy (for $\mathrm{X}_{\mathrm{gen}}$ ) [_ gen to manipulate the data]), 
- arbitrary control: there is no local controller ([_arb to smoke around babies is $_{i}$ dangerous for them ${ }_{i}$. $^{3}$

This section deals only with the general properties. The predicate-specific readings are dealt with in section 9.

6.1 Are there instances of partial control?

Partial control may be tested with collective predicates such as meet or gather, which require plural actants (in semantic terms).

6.2 Are there instances of split control?

6.3 Are there instances of arbitrary control?

Usually, arbitrary control does not occur with SOA-objects; however, some SOA-subjects may exhibit arbitrary control with certain predicates. It is unclear whether there are languages that have predicates which instantiate arbitrary control with SOA-objects.

6.4 Which control readings are possible in WH-control if the language exhibits WH-control?

Often, control readings seem to be loosened compared to control in declarative SOA-arguments. It is therefore important to check whether WH-control may occur with exhaustive, partial, split or abitrary control.

\section{Control shift}

As has been observed in the literature (e.g. Růžička 1983, 1999, Comrie 1984), some (transitive) control verbs may shift the controller (from subject to object control or vice versa) under certain circumstances. It is helpful to determine first which structures may trigger control shift - if the language allows control shift. In the second step, the lexical predicates that allow control shift should be determined (see 9.4). It is important to keep in mind that there is a gradual difference between predicates of variable control (e.g. propose) and predicates that may shift. The latter generally require a strong trigger for a control shift, whereas the former at most need contextual support for a certain control reading.

7.1 May a control shift be induced by non-active voice (e.g. passive) on the embedded predicate or on the matrix predicate?

Passive has been attested as a weak trigger for control shift. Besides the wellknown cases of control shift with passivized embedded verbs, passivization of

3 Arbitrary control can be interpreted generically. Generic readings may arise from generically bound implicit controllers in the matrix predicate and from generic interpretations of non-controlled (= arbitrary) arguments. 
the matrix predicate may also require a control shift: polyadic subject control verbs may have to undergo control shift if they are passivized, as the following German example illustrates.

(12) a. ?? $\operatorname{Ihm}_{\mathrm{i}}$ wurde versprochen, [ _ j das Auto zu reparieren]. he.DAT was promised the car to repair.INF lit. 'he was promised to repair the car'

b. $\operatorname{Ihm}_{\mathrm{i}}$ wurde versprochen [ ${ }_{\mathrm{i}}$ das Auto reparieren $\mathrm{zu}$ dürfen]. he.DAT was promised the car repair.INF to be.allowed.INF 'he was promised to be allowed to repair the car'

7.2 Are there instances of control shift if the dependent verb is embedded under a modality operator (e.g. deontic mood) or a modal expression (e.g. to be allowed to) - either explicitly or implicitly?

7.3 Are there instances of control shift if the embedded predicate is nonagentive?

Recipient-oriented predicates such as bekommen 'get' may trigger a control shift with some predicates.

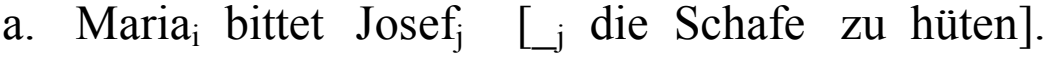 $\mathrm{M}$ asks $\mathrm{J}$ the sheep to tend.INF
'Mary asks Joseph to tend the sheep' [object control]
b. Maria ${ }_{i}$ bittet Josef $f_{j}[i$ ein neues Auto $z$ bu bekommen]. $M$ asks $J$ a new Car to get.INF
'Mary asks Joseph to get a new car' [subject control]

7.4 Do object control verbs shift to subject control if their internal argument is left implicit (compare English shout vs. ask)?

7.5 For languages that instantiate a switch-reference system in control structures: Can a change in the switch-reference marker trigger a control shift?

7.6 Does the language show other patterns of control shift?

\section{Control and clause union}

Provided that the respective language allows clause union (restructuring), the question arises whether there is any correlation between control and clause union. Data from the literature have already revealed that the various control verbs do not behave homogeneously regarding clause union and that there is no neat correlation between control reading and clause union. Nevertheless, there may be languages that show some kind of correlation between control and clause union. It is, however, important to check whether any observed correlation is one 
that relates the control property to clause union and not some other property of the control predicate (e.g. its linking pattern).

8.1 Which clause union effects show up in the respective language?

Here is a list of some clause union effects observed in the literature:

- movement of a constituent out of the embedded clause into the matrix clause (including elements such as argumental or adverbial clitics; see (14))

- agreement of the control verb with an argument of the embedded verb; see (15)

- linking effects due to some trigger on the control verb; see (16)

In Hungarian, some control verbs attract the preverb of an embedded verb if they do not have a preverb on their own and nothing else appears in the preverbal focus position.

(14) Hungarian

a. Anna el-akar-ja [olvas-ni a könyv-et]

A. PV-want-3SG.DEF read-INF the book-ACC

'Anna wants to read the book'

b. * Anna el-szeret-i [olvas-ni a könyv-et]

A. PV-love-3SG.DEF read-INF the book-ACC

'Anna loves to read the book'

c. Anna szereti [ el-olsvasni a könyvet]

In Basque, the two subject control verbs nahiago 'want more, prefer' and nahi 'want' differ in their clause union patterns; the former excludes clause union (agreement with the embedded DAT-argument), the latter requires it.

(15) Basque (Hualde \& de Urbina 2003:697/695)

a. Amaiak [niri liburu bat erosi] nahiago

A.ERG 1SG.DAT Book one buy.PTC want.more

$\mathrm{du} / \quad *$ dit

AUX.3SG.E/3SG.N/ AUX.3SG.E/1SG.D/3SG.N

'A. prefers to buy me a book'

b. [gurasoei Bilbon etxe bat erosi] nahi

parents.DAT Bilbao.LOC house one buy.PTC want

diet/ *dut

AUX.3N/3PL.D/1sG.E/ AUX.3N/1SG.E

'I want to buy my parents a house in Bilbao'

In Polish, negation of the control verbs triggers genitive on the object of the embedded verb. 
(16) Polish

$\begin{array}{llll}\text { a. Jan kazal Piotrowi } \quad \text { [zamknąc } & \text { okno] } \\ \text { J. ordered } & \text { Peter.DAT close.PERF.INF } & \text { window.ACC } \\ \text { 'Jan ordered Peter to close the window' } & \end{array}$

b. Jan nie kazał Piotrowi [zamykać okna]

J. not ordered Peter.DAT close.IMPERF.INF window.GEN

'Jan didn't order Peter to close the window'

8.2 To what extent do control verbs allow/require clause union with the embedded verb? Please check whether the control verbs behave homogeneously, i.e. whether each control verb allows the same clause union properties.

8.3 Is there any interaction between clause union and the referential dependencies (e.g. such that clause union excludes partial control with verbs that would allow partial control otherwise)?

\section{Lexical classes}

Since the control properties are predicate-specific or predicate-class-specific, careful studies are necessary to determine the various control predicate classes. The lexical classes can be established on a multi-dimensional basis, which includes the controller argument, the distinction of inherent vs. structural control, the referential readings, control shift, and the semantic selection of embedded predicates.

\subsection{Inherent vs. structural control}

A very important class is the class of inherent control predicates, i.e. predicates that require a control reading independent of the syntactic realization of the SOA-argument. One can distinguish three types of inherent control, depending on the types of sentential complementation in the respective language. If the language distinguishes control-inducing and control-neutral structures, there may be inherent control predicates that

- only select control-inducing structures (strong inherent control)

- select control-inducing as well as control-neutral structures without a change in the control readings (weak inherent control)

- only select control-neutral structures, but are restricted to control readings (marked inherent control).

Languages that do not distinguish control-inducing and control-neutral structures only exhibit one class of inherent control predicates without further subclassifications. 
Predicates that only exhibit control readings with control-inducing structures are structural control predicates. Their specific lexical property is their potential to license a control-inducing structure, which may not be possible for all predicates that select a SOA-argument.

9.1.1 Which predicates belong to the class of inherent control predicates? If the language distinguishes control-inducing and controlneutral structure, please differentiate in terms of the following classification:

a) list the predicates of strong inherent control.

b) list the predicates of weak inherent control.

c) list the predicates of marked inherent control.

9.1.2 Which predicates license structural control in languages that exhibit control-inducing structures?

9.1.3 Which SOAA-taking predicates do not license structural control in languages that exhibit control-inducing structures?

\subsection{Classes in terms of the controller argument}

9.2.1 Which predicates function as subject control predicates, which as object control verbs in the unmarked case?

The unmarked case is represented by a SOA-argument headed by an agentive predicate in active voice.

9.2.2 Which predicates do not show any preference regarding subject or object control (= variable control)?

A predicate of variable control should at most require pragmatic or contextual reinforcement in order to trigger all potential control readings.

\subsection{Referential readings}

9.3.1 Which control predicates are restricted to readings of exhaustive control?

9.3.2 Which control predicates allow partial control? Are there predicates that require a partial control reading?

9.3.3 Which control predicates allow split control? Are there predicates that require a split control reading?

\subsection{Control shift}

On the basis of the general properties of control shift dealt with in 7 , it is possible to determine the predicate-specific admissibility of control shift. 
9.4.1 Which polyadic subject control predicates allow a control shift? Does this shift occur in all triggering contexts?

9.4.1 Which object control predicates allow a control shift? Does this shift occur in all triggering contexts?

\subsection{Semantic selection}

The predicate-specific control behavior might also correlate with the semantic selection of the embedded predicate. Jackendoff \& Culicover (2003) suggest that the class of exhaustive control predicates coincides with the class of SOAAtaking predicates that only select agentive predicates ('Action predicates' in their terminology). The following questions highlight dimensions of semantic selection that may correlate with other structural or control properties.

9.5.1 Does the control predicate show any thematic restrictions with respect to the embedded verb (e.g. only agentive verbs or verbs that allow an agentive reinterpretation)?

Directive verbs such as überreden 'persuade' usually only select agentive predicates; non-agentive predicates have to be coerced into an agentive reading. Predicates such as hoffen 'hope' preferentially select non-agentive predicates (??ich hoffe zu tanzen 'I hope to dance' vs. ich hoffe tanzen zu können 'I hope to be able to dance').

9.5.2 Does the control verb show any restrictions with respect to the aspectual class of the embedded verb? Does it allow activity verbs (run), state verbs (know), accomplishment verbs (draw a circle) and achievement verbs (arrive)?

9.5.3 Does the control verb show any restrictions with respect to aspectual, temporal or modal categories on the embedded verb taking the general restrictions for these categories in complementation into account? Which control verbs allow independent time reference in the embedded clause?

Control predicates that do not impose any time dependence on the embedded predicates are believed to show a wider spectrum of control readings, e.g. partial control readings (Landau 2000, Wurmbrand 2001).

\subsection{Evaluation of classes}

The evaluation of the lexical classes should include a cross-classification of the various dimensions mentioned in this section, i.e. which predicates share certain properties in terms of inherent vs. structural control, in terms of the controller argument, the referential readings, the control shift, and the semantic selection. 
A cross-classification along these lines is purely structural and thus independent of traditional nations of semantic/lexical fields.

\section{List of SOAA-taking predicates}

This is an exemplary list of SOAA-taking predicates; this list is not meant to be exhaustive; it is suggested as a starting point for the investigation of possible control predicates. Note that languages may display control predicates that are not covered by the following classes. Moreover, the proposed verb classes are not meant as structural classes. See also Noonan (1985) for complement-taking predicates, Pollard \& Sag (1994) and Landau (2000) for control verbs.

10.1 desiderative predicates: want, prefer, yearn, arrange, hope, be afraid, refuse, agree, plan, aspire, decide, mean, intend, wish, need, long, expect, resolve, strive, demand, choose, offer, be eager, be ready,

Note that Noonan distinguishes three classes of desideratives: 'hope class', 'wish class', 'want class'.

10.2 directive/manipulative predicates: cause, force, make, persuade, tell, threaten, let, cajole, command, order, request, ask, press, charge, command, induce, compel, signal, forbid, prevent (from), enable ...

10.3 implicative predicates/achievement predicates: manage, chance, dare, remember to, happen to, get to, try, forget to, fail, avoid, refrain, decline, neglect, ...

10.4 factive/commentative predicates/experiencer-subject verbs: regret, hate, be sorry, be glad, like, dislike, loath, be surprised, be shocked, ...

10.5 experiencer-object verbs: thrill, amuse, cheer, satisfy, sadden, ...

The following predicate classes mainly function as raising predicates. However, some of them may have a usage as control predicate as well, which needs to be checked carefully.

10.6 phasal predicates/aspectual verbs: begin, start, continue, keep on, finish, stop, cease ...

10.7 modal predicates: can, be able, ought, should, may, be obliged, must, ...

10.8 perception predicates: see, hear, watch, feel, sense, smell ...

The following predicates are generally not predicates of inherent control. Some languages, however, may allow structural control with these predicates. 
10.9 propositional (attitude) predicates: claim, believe, think, suppose, assume, doubt, deny, ...

10.10 utterance predicates/verbs of communication: tell, say, report, promise, ask, ...

Depending on whether the language exhibits WH-control, interrogatives have to be studied in terms of their control behavior.

10.11 interrogative predicates: wonder, ask, find out, interrogate, inquire, contemplate, deliberate, guess, grasp, understand, know, be unclear, ... 